\title{
Feasibility for the implementation of the MENtorship Program
}

\author{
Kevin J. Milligan * Gordon L. Gillespie \\ College of Nursing, University of Cincinnati, Cincinnati, United States
}

Received: May 23, 2017

DOI: $10.5430 /$ jnep.v7n11p84
Accepted: June 19, 2017

Online Published: June 28, 2017

\begin{abstract}
Objective: Men comprise only $9 \%$ of the U.S. nursing workforce and $15 \%$ of baccalaureate nursing students. The odds of male nursing students completing nursing school are significantly lower than that of female nursing students. Mentoring programs designed to improve male nursing student retention are needed. This study was conducted to evaluate the feasibility of a novel "MENtorship" Program for men in nursing school.

Methods: This study used a sequential QUAN-qual explanatory mixed methods design in two phases: (1) quantitative web-based surveys were sent to all participants $(n=19)$ to assess mentor/mentee relationships; and, (2) qualitative interviews were conducted to explain the survey results. Data were analyzed thematically, and data source triangulation was done by comparing the qualitative findings to the quantitative findings.

Results: Findings included high perceived commitment from mentors and mentees. Participants described multiple program benefits and recommended program improvements. One key recommendation is to provide a thematic focus to each mentor/mentee meeting (i.e. professionalism, ethics, nursing specialties).

Conclusions: The MENtorship Program pilot was deemed feasible for future implementation.
\end{abstract}

Key Words: Mentorship, Men in nursing, College of nursing, Diversity

\section{INTRODUCTION}

Men comprise only $9 \%$ of the U.S. nursing workforce ${ }^{[1]}$ and only $15 \%$ of baccalaureate nursing students. ${ }^{[2]}$ The 2010 report from the Institute of Medicine, ${ }^{[3]}$ "The Future of Nursing," specifically calls for increasing the gender diversity of the nursing workforce: "While more men are being drawn to nursing, especially as a second career, the profession needs to continue efforts to recruit men; their unique perspectives and skills are important to the profession and will help contribute additional diversity to the workforce."

Efforts to increase the pipeline of men entering the nursing profession are challenging, because men are not only less likely to go into nursing, they are less likely than women to be successful in nursing school. Once men are recruited into undergraduate nursing programs, the odds of them not completing their program are nearly twice (OR: 1.93) that of female nursing students. ${ }^{[4]}$ Reasons attributed to male nursing student attrition are the unique challenges they face due to their minority gender status: role strain, isolation, suspicion surrounding intimate touch, and sexual stereotyping. ${ }^{[5,6]}$ While the overall number of men in nursing is increasing, male attrition from nursing school is a key barrier to maximizing the gender diversity of the nursing workforce.

To promote gender diversity, the barriers men face in nursing States.

${ }^{*}$ Correspondence: Kevin J. Milligan; Email: milligkj@mail.uc.edu; Address: College of Nursing, University of Cincinnati, Cincinnati, United 
school need to be prevented or mitigated..$^{[5,7]}$ Communities of support, such as mentoring programs, are a wellrecognized strategy to prevent attrition and foster professional nursing practice. ${ }^{[7-12]}$ Mentoring was broadly based in this program and "concentrates on developing areas such as career progression, scholarly achievements, and personal development. Mentoring relationships are based around developing reciprocity and accountability between each partner". [13] While mentorship programs for nursing students have been shown to be successful, ${ }^{[1]}$ nursing mentorship programs generally have few male participants, if any. ${ }^{[12]}$ The purpose of this paper is to report the feasibility of a mentorship program designed specifically to support male nursing students.

\section{MethodS}

This study used a sequential QUAN-qual explanatory mixed methods design. The QUAN (quantitative) phase used surveys to determine the quality of the mentor-mentee relationships. The qual (qualitative) phase used individual interviews to explain the survey results and identify specifically what went well, what could be better, and recommend improvements to the mentoring relationships and the overall program. The study took place in a Midwestern United States college of nursing undergraduate program. The sample consisted of male undergraduate nursing students and male registered nurses who participated in the MENtorship Program.

\subsection{MENtorship Program}

All male nursing students were invited to participate in the MENtorship Program via email, in-person solicitations, and college chapter meetings of the American Assembly for Men in Nursing. Mentors were recruited from the two local academic medical centers by the leadership of a local chapter of the American Assembly for Men in Nursing. The MENtorship Program itself was designed combining traditional and group models of mentorship. ${ }^{[14]}$ Participants experienced the one-on-one interaction of a traditional mentorship program while simultaneously clustered into mentor-mentee "families".

The MENtorship Program consisted of 5 "families" with 14 nursing students and 5 registered nurses employed at two hospitals adjacent to the college of nursing. Each family consisted of four men: a registered nurse, senior or junior nursing student, sophomore nursing student, and freshmen pre-nursing student. Using family (group) mentorship, the nursing student participants received mentorship from the experience level directly above their own; and registered nurses, senior nursing students, and junior nursing students provided mentorship to the students directly below their own. This "reach back, pull forward" program model allowed for individualized attention as well as interaction within the small group context.

Recruitment for the MENtorship Program included recruitment flyers, emails, and word of mouth. All men interested in the program filled out an application that asked about their education level, weekly schedule and availability, nursing specialty of interest, and self-reported enthusiasm about being a mentor and/or mentee (1-10 Likert scale). Mentormentee dyads were assigned on the basis of these criteria.

The program launched with an orientation session during Spring semester 2013. During orientation, mentors and mentees were introduced, ground rules were described, and program goals were discussed. General rules for the program included: no gift giving (including meals or beverages), make reasonable accommodations in the event of a cancellation, and no tutoring (or direct academic support). Mentors were encouraged to lead discussions and experiences related to leadership, professional development, shadowing, alternative perspectives, and reflection. Beyond this general guidance, mentor-mentee interactions were left largely unstructured to allow participants the ability to tailor the program to their own interests and needs. Each mentor-mentee pairing was encouraged to meet at least three times during the pilot program period.

\subsection{Study procedures}

Prior to study initiation, the university Institutional Review Board examined the study protocol and deemed the study quality improvement and "non-human subjects research". After this determination and conclusion of the MENtorship Program, an invitation to complete the study survey was emailed during Summer to MENtorship Program participants using a web-based collector. The "Assessment of the Relationship with the Mentor" ${ }^{\text {"[12] }}$ was provided to all nursing student participants. The "Assessment of the Relationship with the Mentee" ${ }^{[12]}$ was provided to all registered nurse participants and nursing students (juniors, seniors) who served as mentors to other nursing students. All responses were directly entered into a web-based collector by participants. The data were securely downloaded and imported into IBM SPSS Statistics 23 (Armonk, NY) for quantitative analysis. Next, all participants were invited to participate in a single one-on-one interview. The interviews were conducted by the first author using an interview guide. All interviews were audio recorded and transcribed verbatim. Transcripts were verified for accuracy while simultaneously listening to the audio recording. The transcripts were imported into NVivo 10 (Burlington, MA) for qualitative analysis. 


\subsection{Instrumentation}

The study instruments were developed by Grindel and Hagerstrom $^{[12]}$ for use with new and experienced nurses for a mentorship program called Nurses Nurturing Nurses. The first instrument, "Assessment of Relationship with Mentor", is a 25-item survey to measure mentees' perceptions about the availability of their mentor; mentor's ability to listen objectively; and mentor's ability to offer conflict resolution suggestions, career development, communication, etc. Items were Likert-scaled ranging from 0 (not at all) to 4 (very much). Survey items were summed to yield a mentor relationship score ranging from 0 to 100 with higher scores indicating a more positive relationship with a mentor. Items marked as "Not applicable" were coded as "0" for the summative score. This survey was previously deemed reliable with an internal consistency reliability of 0.94 . The second instrument, "Assessment of Relationship with Mentee", is a 24-item survey to measure mentors' perceptions of their mentee's motivation to make contacts, strategize, communicate, manage conflict situations, accept constructive criticism, etc. Items were Likert-scaled ranging from 0 (not at all) to 4 (very much). Survey items were summed to yield a mentee relationship score ranging from 0 to 96 with higher scores indicating a more positive relationship with a mentee. Items marked as "Not applicable" were coded as "0" for the summative score. This survey also was previously deemed reliable with an internal consistency reliability of 0.99 . Participants also completed a demographic questionnaire stating their race, class/rank, age, number of meetings attended by mentors and mentees, and self-reported and perceived commitment of mentors and mentees. Commitment was rated using a Lik- ert scale ranging from 0 (no commitment) to 10 (complete commitment).

\subsection{Data analysis}

Descriptive statistics were calculated for class/rank, race, age, number of meetings attended, and perceived commitment of mentors and mentees. Mean summative scores were computed for each survey. The qualitative transcripts were analyzed using a constant comparative analysis method based on the work of Lincoln and Guba, ${ }^{[15]}$ including line-by-line coding.

\subsection{Trustworthiness}

Trustworthiness was managed through investigator triangulation, the generation of an audit trail, and data source triangulation. Investigator triangulation was accomplished by both researchers independently analyzing the qualitative transcripts. An audit trail was generated to track the evolution of the coding schema and coding decisions. Data source triangulation was done by comparing the qualitative findings to the quantitative findings.

\section{RESULTS}

\subsection{Quantitative findings}

Twelve students and four registered nurses responded to the study survey. All respondents were male and white. Respondents' average age was 24.7 years ranging from 19 to 42 years. Of the respondents, four students served as mentees only, eight students served as both mentees and mentors, and four registered nurses served as mentors only (see Table 1).

Table 1. Descriptive statistics for the demographic characteristics of the mentees and mentors

\begin{tabular}{lll}
\hline & N (\%) & Mean (range) \\
\hline Class/rank & $3(18.8)$ & \\
Freshman & $4(25.0)$ & \\
Sophomore & $2(12.5)$ & \\
Junior & $3(18.8)$ & \\
Senior & $4(25.0)$ & $24.7(19-42)$ \\
Registered nurse & & $27.5(25-30)$ \\
Age & & \\
Students & & $2.6(0-5)$ \\
Registered nurses & & $2.6(0-6)$ \\
Number of meetings & & $8.7(5-10)$ \\
Mentee meetings with their mentors & & $9.2(7-10)$ \\
Mentor meetings with their mentees & & $8.1(5-10)$ \\
Commitment to program participation & & $7.4(2-10)$ \\
Mentees' self-reported commitment & & \\
Mentees' perception of mentor commitment & & $59.2(22-89)$ \\
Mentors' self-reported commitment & & $64.4(7-94)$ \\
Mentors' perception of mentee commitment & & \\
Mentor-mentee relationship summative scores & & \\
Perceptions of mentee relationship score & & \\
Perceptions of mentor relationship score & & \\
\hline
\end{tabular}




\subsection{Mentors perceptions about the mentor-mentee rela-} tionship

Mentors rated their personal commitment to the MENtorship Program high with a mean of 8.1 out of 10 . Mentors rated the commitment of their mentees high with a mean of 7.4 out of 10. The summative score for their perceptions of the relationship with their mentees was 59.2 out of 96 indicating moderate positive relationships (see Table 1).

Several positive activities were reported on the survey by mentors related to the actions of their mentees. The majority $(n=9)$ of mentors had mentees who kept appointments at least "quite a bit" that were scheduled with them. During meetings, primary foci rated as "quite or bit" or "very much" were discussing mentees' future potential as a registered nurse $(n=9)$, discussing immediate learning needs $(n=8)$, strategically setting professional goals $(\mathrm{n}=7)$, and discussing long-range career planning $(n=7)$. Several activities were deemed not applicable by mentors. Examples of these activities are setting up professional introductions for mentees ( $\mathrm{n}$ $=4)$, mentees calling mentors $(n=2)$, discussing challenging patient situations $(\mathrm{n}=2)$, and talking about clinical decisions $(\mathrm{n}=2)($ see Table 2).

Table 2. Mentors' $(\mathrm{n}=11)$ perceptions about their mentees*

\begin{tabular}{|c|c|c|c|}
\hline & Not applicable/Not at all & A little/Somewhat & Quite a bit/Very much \\
\hline Mentees kept appointments to talk with mentors & 1 & 1 & 9 \\
\hline Mentees initiated telephone calls with mentors & 4 & 4 & 6 \\
\hline Mentees participated in professional goal strategizing & 0 & 4 & 7 \\
\hline Mentees followed up on professional introductions & 5 & 1 & 4 \\
\hline Mentees seemed confident in mentors abilities & 0 & 0 & 8 \\
\hline Mentees discussed their long-range career planning & 0 & 4 & 7 \\
\hline Mentees discussed challenging patient situations & 2 & 4 & 5 \\
\hline Mentees talked about being a patient advocate & 1 & 4 & 6 \\
\hline Mentees talked about clinical decisions made & 4 & 2 & 5 \\
\hline Mentees valued mentors' discussions & 0 & 2 & 9 \\
\hline Mentees discussed immediate learning needs & 0 & 3 & 8 \\
\hline Mentees inquired about workings of clinical agencies & 1 & 2 & 8 \\
\hline Mentees discussed their future potential & 1 & 1 & 9 \\
\hline Mentees were participative in mentor-mentee program & 0 & 2 & 9 \\
\hline
\end{tabular}

* One student who was both a mentor and mentee did not complete the study survey.

3.3 Mentees perceptions about the mentor-mentee relationship

Mentees rated their personal commitment to the MENtorship Program high with a mean of 8.7 out of 10 (see Table 1). They also rated the commitment of their mentors very high with a mean of 9.2 out of 10 . The summative score for their perceptions of the relationship with their mentors was 64.4 out of 100 indicating moderate positive relationships.

Several positive activities were reported by mentees related to the actions of their mentors. The majority $(n=10)$ of mentees had mentors who were available to talk or meet with them when needed at least "quite a bit". During meetings, primary foci rated as "quite or bit" or "very much" were mentors guiding mentees in assessing their learning needs (n $=9$ ), guiding mentees in their future potential as a registered nurse ( $n=9)$, and offering insights into the workings of clinical agencies $(n=8)$. Nearly all $(n=10)$ of the mentors were perceived as caring about the mentees at least "quite a bit" Published by Sciedu Press and serving as role models for mentees $(n=9)($ see Table 3$)$.

\subsection{Qualitative findings}

Ten students and two registered nurses participated in the interviews. Three themes were derived from the interview data: Framework for MENtorship, Process of MENtorship, and Outcomes of MENtorship. Each theme consisted of two or more subthemes.

Framework for MENtorship describes the structure and logistics of the mentoring experience. There were two subthemes for Framework for MENtorship. In subtheme 1, "Add Structure Without the Homework", respondents gave recommendations for planning the program during the next academic year starting the program in the fall semester, establishing goals and outcomes, adding structure to the program, setting objectives, and balancing the amount of time for individual mentor-mentee meetings with group meetings. An example for this subtheme describing more formality is "Have 
a theme for each meeting. So you have like meeting 1, 2, 3,4 , you know schedule like that, and then have questions that are different for each week, that convert to those topics". In relation to one-on-one versus group meetings, one senior student said, "...we decided that we would do all of our meetings together. So I only had one meeting with my mentor that wasn't with my mentee and his mentee." In subtheme 2, "Perfect and Mucky Scheduling", respondents discussed scheduling logistics for the mentor-mentee and group meetings in relation to when, where, and who. A common report was by one student who said, "It was hard to find time...I think we had totally opposite schedules." A recommendation to address this concern was to schedule a standing meeting "...every second Tuesday of the month. Something where you can plan ahead, so it's easy like that."

Table 3. Mentees' $(\mathrm{n}=11)$ perceptions about their mentors*

\begin{tabular}{llll}
\hline & Not applicable/Not at all & A little/Somewhat & Quite a bit/Very much \\
\hline Mentors were available to talk/meet & 0 & 1 & 10 \\
Mentors talked about professional development & 1 & 3 & 7 \\
Mentors helped mentees strategize professional goals & 2 & 1 & 7 \\
Mentors assisted with professional introductions & 1 & 4 & 5 \\
Mentors assisted with long-range career planning & 1 & 3 & 7 \\
Mentors discussed challenging patient situations & 3 & 2 & 6 \\
Mentors encouraged mentees to be patient advocates & 4 & 1 & 4 \\
Mentors talked about mentees clinical decisions & 5 & 2 & 10 \\
Mentors demonstrated caring about mentees & 0 & 1 & 9 \\
Mentors guided mentees in assessing learning needs & 2 & 0 & 8 \\
Mentors offered insights into clinical agencies & 1 & 2 & 9 \\
Mentors guided mentees in assessing future potential & 2 & 0 & 9 \\
Mentors were role models for mentees & 0 & 1 & 10 \\
Mentors were supportive overall of mentees & 0 & 1 & 9 \\
\hline
\end{tabular}

* One student who was both a mentor and mentee did not complete the study survey.

Process of MENtorship describes the content of communications and interactions, as well as the medium of communications. There were two subthemes for Process of MENtorship. In subtheme 1, "Topics of Discussion", participants described the "what" of the mentor-mentee meetings including roles of a nurse and soft skills like interviewing, resume building, preparation and tips for the future, and "how to survive". Additional topics of discussion included "who are the good and bad teachers", "when to go into advanced practice", and "different interview styles". In subtheme 2, "Communication", respondents imparted the "how" of the mentor-mentee discussions including asking questions, sending emails and texts, and writing note cards. Examples of communication were the students and registered nurses having "an active email going between all of us" and one nurse mentor giving his mentee "a bunch of note cards that he had for pharmacology" (see Table 4).

There were three subthemes for Outcomes of MENtorship. In subtheme 1, "Quality of MENtorship Experience", respondents explained the general or specific merits of the program. One participant said, "I think we talked about a lot of things that were beneficial." In subtheme 2, "Professional Benefits", respondents identified the benefits of participation which in cluded being a role model/mentor, actualizing what it will be to be an upperclassman (e.g., junior, senior), learning from others' mistakes, shadowing a nurse, and gaining new perspectives about nursing school and the nursing profession. An example of nurse shadowing by one student was: “...it's really good to get skills down, but you don't really see how the nurse operates. Like what the routine is and what the responsibilities are and like something other than med/surg... So we kind of went out. I shadowed in PACU [post anesthesia care unit]. I shadowed in OR [operating room]. I shadowed in the floor." In subtheme 3, "Male Camaraderie", respondents communicated how relationships were encouraged, friendships were made, and social activities were held. One of the social activities was a group paintball session: "It was cool for me too, because we went paintballing and all that kind of stuff. So we actually did some other stuff, too. I really like that." The antithesis of this subtheme was the difficulty in establishing a connection. One student said, "I think he [senior student mentor] was more concerned with getting out of school and getting into Children's for a shadowing experience; at least when I was around. So a lot of his energy was spent talking to [registered nurse mentor] trying to get this set up. So what I got from [senior student mentor] wasn't a great deal, I guess." 
Table 4. Themes and subthemes of the qualitative findings

\begin{tabular}{lll}
\hline Theme & Subtheme & Description \\
\hline \multirow{2}{*}{$\begin{array}{l}\text { Framework for } \\
\text { MENtorship }\end{array}$} & Add Structure Without the Homework & $\begin{array}{l}\text { Program planning, establishing goals and outcomes, add } \\
\text { structure to the program, meeting objectives. }\end{array}$ \\
\cline { 2 - 3 } & Perfect and Mucky Scheduling & Scheduling logistics (when, where, who). \\
\cline { 2 - 3 } $\begin{array}{l}\text { Process of } \\
\text { MENtorship }\end{array}$ & Topics of Discussion & The “what” of the mentor-mentee discussions. \\
\hline Outcomes of & Quality of the MENtorship Experience & General and/or specific description of the merits of the program. \\
MENtorship & Professional Benefits & The benefits and/or perks of participation. \\
\cline { 2 - 3 } & Male Camaraderie & Encouraging relationships, friendship, social dynamics. \\
\hline
\end{tabular}

\section{DISCUSSION}

The MENtorship Program was deemed feasible for future implementation. During the program's two-month pilot period, mentors and mentees met on average two to three times indicating that program participants met approximately every two weeks. The frequency of the meetings was likely a byproduct for the high level of commitment for both mentors and mentees. While the program was deemed feasible, program changes are needed prior to its launch during a successive academic year.

Scheduling conflicts were a key barrier to the MENtorship Program, not surprising considering the hectic schedule of nurses and nursing students. While these scheduling conflicts were apparent in some of the mentor-mentee dyads in this study, mentors were generally rated as being highly available. On the program application form, participants were able to state their most available times of the week-this was heavily considered during the match-making process, but this process was not perfect. Some of the schedules changed dramatically from the time the applications for the program were submitted to the time of program implementation. Scheduling conflicts are primarily prohibitive in person-to-person meetings and communications. The mentoring process should not be confined to in-person interactions, and by using other mediums of communication, mentor-mentee dyads could effectively mitigate scheduling difficulties. ${ }^{[16]}$ Examples of alternative mediums are Skype, FaceTime, email, text messaging, and telephone. An additional strategy to facilitate meetings between mentors and mentees include scheduling standing meetings, such as the first and third Monday evening of every month while school is in session. Rather than matching mentors with mentees based on common availability, a better strategy would be to match dyads based on practice interest such as medical/surgical nursing or emergency nursing. Matching dyads based on practice interests could encourage flexibility of the participants to find common times to meet in person.

Mentoring involves establishing a professional-oriented inter-

Published by Sciedu Press personal relationship. ${ }^{[17]}$ A negative consequence of scheduling conflicts was mentees failing to connect with their mentors on a personal level. It is difficult to establish a meaningful connection with someone if the person is physically absent. Failure to establish an interpersonal connection with a mentor, or mentee, was a barrier to participants having a positive experience in this program pilot. A recommendation to facilitate an early connection between mentors and mentees is to require attendance to the program's orientation session. Scheduling and keeping meetings needs to be emphasized in the first several weeks of the program. All participants should be held accountable for keeping meetings once they are scheduled.

Both individual and group meetings were encouraged in the MENtorship Program. Some participants naturally preferred a group dynamic, while others preferred smaller, more personal connections. This preference may be related to a person's innate preference for introversion versus extroversion. ${ }^{[18]}$ This preference became apparent during the context of peer mentoring. Some student participants desired more personalized mentoring, while others gravitated towards participation within the group context of the mentoring "family". Both individual and group attention has been shown to be valuable in other mentoring programs. ${ }^{[14]}$ At the launch of the MENtorship Program, mentors and mentees should purposefully discuss the dynamic that will work the best for them. Coordinators of the program can host events that facilitate team-building within the family so that mentormentee dyads can schedule more individualized interactions. Alternatively, participants can be asked on their program application form if they prefer individual or group dynamics-this preference can be taken into consideration during the mentor/mentee matching process.

Participants who connected with their mentor, mentee, and/or "family" rated the experience positively and found encouragement and benefit from the program. This finding reflects the importance of participants developing the interpersonal relationship early in the program as well as the program con- 
tinuing long enough for the relationships to develop naturally. The MENtorship Program provided the medium to discuss concerns, challenges, and solutions for classroom and/or clinical situations (e.g., role strain, sexual stereotyping, suspicion surrounding intimate touch) that students perceived were a result of their being male in a predominantly female profession with men who also experienced similar challenges. While conversations were not exclusive to these challenges, the program format allowed students to voice their concerns and receive support from other men when necessary. During a future iteration of this program, the challenges that men in nursing experience as a result of being male should be openly discussed. Participants will be made aware that the mentor-mentee dyads and "families" were created to be safe places to express these concerns.

In addition to addressing issues of scheduling and relationship building, participants desired some form of structure to guide their interactions. Most participants in the MENtorship Program were students, many of which have never had formal mentoring preparation. Accordingly, mentors may have felt unsure of how to engage their mentees in the mentoring dynamic. Providing formal structure to the program, at least initially, was something frequently suggested by participants. The caveat to providing structure is that some students did not want the structure to feel like homework or become burdensome. This caveat is likely due to the already demanding curriculum of nursing school, and student participants not wanting the program to divert their attention from focusing on their nursing studies; therefore, it is important to create an environment that facilitates productive mentorship without the program becoming an extension of their school work. Structure without homework can be built into the program by having the mentor-mentee "families" focus on a designated topic each month. A deeper dive of the topic can be discussed within the mentor-mentee dyads. Topics can include professional development, offering new perspectives, overcoming challenges, success in classes, transitioning to professional practice, etc. These guided topics are important when initiating new mentor-mentee relationships, but may not be needed once the relationships have developed and the dyads are able to establish their own mentoring dynamic and identify their own topics of discussion.

The feasibility pilot for the MENtorship Program lasted two months. Participants recommended a long-term program to allow the mentoring process to continue. As mentioned before, schedules can be difficult to navigate. Furthermore, the more time spent building interpersonal connections, the more effective the mentor-mentee dynamic. Prolonging the program over the course of a full academic year can provide enough time for connections to be established and true mentoring to occur. Optimally, mentor-mentee dyads and "families" will be matched within the first few weeks of fall semester. In order to match mentors and mentees early in the semester, MENtorship Program coordinators would need to recruit participants at freshmen orientation and first class sessions. The program then can be formally closed at the end of each academic year with a celebratory get together prior to final examinations week to acknowledge retention in the nursing program as well as the MENtorship Program.

\section{Limitations}

There are two key limitations to this project: small sample size and one project site. Both limitations reduce the generalizability of the project findings. Of note, the intent of this project was to evaluate the feasibility for implementing the program in a single college of nursing. While the project had limitations, the ultimate goal of the project was achieved.

\section{Conclusion}

The MENtorship Program was successfully implemented over a two-month time period. Refinement of the program such as scheduling group meetings, adding structure to mentor-mentee meetings, and prolonging the program over the course of a full academic year can lead to increased effectiveness of program goals as well as deeper connections between mentors and mentees. In addition, issues related to scheduling and preference for dyad versus "family" meetings need to be addressed prior to or during the program orientation session. Future research is needed to determine the long term outcomes of this mentorship program and to evaluate if the participants effectively acclimated to being men in nursing.

\section{ACKNOWLEDGEMENTS}

The authors wish to acknowledge William Lecher, DNP, MS, MBA, RN, NE-BC, former president of the American Assembly for Men in Nursing for his critical role in establishing the MENtorship Program.

\section{CONFLiCTS OF INTEREST Disclosure}

The authors declare that there is no conflict of interest.

\section{REFERENCES}

[1] National Center for Health Workforce Analysis, Bureau of Health Professions, Health Resources and Health Administration. Sex, Race, and Ethnic Diversity of U.S. Health Occupations (2010-2012). [In- ternet]. 2015 Jan [cited 2017 May 9]. Washington DC. Available from: https://bhw.hrsa.gov/sites/default/files/bhw/n chwa/diversityushealthoccupations.pdf 
[2] Annual survey of schools of nursing, academic year 2013-2014 [Internet]. Washington, DC: National League for Nursing; 2014 [cited 2017 May 8]. Available from: http://www.nln.org/news room/nursing-education-statistics/annual-survey-o f-schools-of-nursing-academic-year-2013-2014

[3] Institute of Medicine. The future of nursing: Leading change, advancing health. 2010 Oct 5: 209.

[4] Salamonson Y, Everett B, Cooper M, et al. Nursing as first choice predicts nursing program completion. Nurse Education Today. 2014 Jan; 34(1): 127-131. https ://doi .org/10.1016/j.nedt. 2012 . 10.009

[5] Juliff D, Russell K, Bulsara C. Male or nurse what comes first? Challenges men face on their journey to nurse registration. Australian Journal of Advanced Nursing. 2016 Dec; 34(2): 45-52.

[6] MacWilliams B, Schmidt B, Bleich M. Men in nursing. American Journal of Nursing. 2013 Jan; 113(1): 38-44. https://doi.org/ 10.1097/01.NAJ .0000425746.83731.16

[7] Bleich M, MacWilliams B, Schmidt B. Advancing diversity through inclusive excellence in nursing education. Journal of Professional Nursing. 2014 Sep 10; 31(2): 89-94. https://doi.org/10.101 $6 / j$.profnurs.2014.09.003

[8] AMSN mentoring program: Site coordinator guide [Internet]. Pitman, NJ: Academy of Medical-Surgical Nurses. 2012 [cited 2017 May 8]. Available from: http://www.amsn.org/sites/defau lt/files/documents/professional-development/mento ring/AMSN-Mentoring-Coordinator-Guide.pdf

[9] Faiman B. Overview and experience of a nursing e-mentorship program. Clinical Journal of Oncology Journal. 2011 Aug; 15(4): 418423. https://doi.org/10.1188/11.CJON.418-423
[10] Faiman B, Miceli T, Richards T, et al. Survey of experiences of an e-mentorship program: Part II. Clinical Journal of Oncology Journal. 2012 Feb; 16(1): 50-54. https://doi.org/10.1188/12. CJON . 50-54

[11] Gilmour J, Kopeikin A, Douche J. Student nurses as peer-mentors: Collegiality in practice. Nurse Education in Practice. 2007 Jan; 7(1): 36-43.

[12] Grindel C, Hagerstrom G. Nurses nurturing nurses: Outcomes and lessons learned. MEDSURG Nursing. 2009 May; 18(3): 183-187, 194. PMid: 19591366

[13] Meier S. Concept Analysis of Mentoring. Advances in Neonatal Care 2013 Oct; 13(5): 341-345. https://doi.org/10.1097/ANC. Ob $013 \mathrm{e} 3182 \mathrm{a} 14 \mathrm{ca} 4$

[14] Mentoring models [Internet]. New York: Rochester Institute of Technology. Available from: https://www.rit.edu/academic affairs/facultydevelopment/faculty-mentoring/mento ring-models

[15] Lincoln Y, Guba E. Naturalistic inquiry. Newbury Park, CA: SAGE Publications; 1985.416 p.

[16] Knouse S. Virtual mentors: Mentoring on the Internet. Journal of Employment Counseling. 2001 Dec; 38(4): 162-169. https: //doi.org/10.1002/j.2161-1920.2001.tb00498.x

[17] Grossman S. Mentoring in nursing: A dynamic and collaborative process. New York, NY: Springer Publishing Company; 2012. 212 p.

[18] Dougherty T, Cheung Y, Florea L. The role of personality in employee developmental networks. Journal of Managerial Psychology. 2008 Aug; 23(6): 653-669. https://doi.org/10.1108/026839 40810894738 